\title{
ROLE OF DIAGNOSTIC LAPAROSCOPY IN NON SPECIFIC ABDOIMINAL PAIN
}

\section{Dr Ashutosh}

Pancholi*

\section{Dr Saurabh}

\section{Gupta}

Assistant Professor,dept of general surgery, SMS Medical College jaipur,Rajasthan,India,302015. *Corresponding Author

Resident, dept of general surgery, SMS Medical College, jaipur,Rajasthan, India, 302015

INTRODUCTION: Abdominal pain is very common presentation in emergency department. It is vital that the physician has an understanding and be familiar with the presentations of common diseases that cause abdominal pain. Patients with acute abdominal pain are a heterogenous group that consumes a great deal of a surgical department's resources.

AIM AND OBJECTIVE: To evaluate the use of the laparoscopy in the diagnosis and management of patients with nonspecific chronic and acute abdominal pain.

MATERIAL AND METHODS: The material consists of patient in all surgical units of P.B.M. and Associated Group of Hospital attached to S.P. Medical College, Bikaner. This study includes 50 patients. In acute NSAP group 21 patients were present and in Chronic NSAP group 29 patients were included.

RESULT: We found that the mean age was 29.38 and 26.17 years in acute and chronic group respectively. In acute group additional $4(19 \%)$ cases had vomiting, $3(14.2 \%)$ had fever, and $2(9.5 \%)$ had both vomiting and fever. While in chronic group $3(10.3 \%)$ cases had vomiting, $2(6.8 \%)$ had fever and $1(3.4 \%)$ case had both vomiting and fever. Efficacy of laparoscopy in chronic group was $86.2 \%$. Laparoscopy made correct diagnosis in $25(86.2 \%)$ cases, $3(10.3 \%)$ cases had normal study and $1(3.4 \%)$ case diagnosed as PID pain was not relieved.

CONCLUSION: Our study establishes role of laparoscopy as a safe and accurate modality in diagnosis of both acute and chronic abdominal pain in cases where diagnosis can't be made with physical examination and non invasive methods.

\section{INTRODUCTION}

Abdominal pain is very common presentation in emergency department. It is vital that the physician has an understanding and be familiar with the presentations of common diseases that cause abdominal pain ${ }^{1,2}$. Patients with acute abdominal pain are a heterogenous group that consumes a great deal of a surgical department's resources. Women of child bearing age commonly present with right iliac fossa pain, most of them do not have appendicitis ${ }^{4}$. Those who do not have the classical features of appendicitis with no evidence of peritonism on examination can be safely managed by active observation or diagnostic laparoscopy ${ }^{4,5}$.

In females of childbearing age, the presence or absence of bilateral tenderness pain migration and vomiting may help to differentiate acute appendicitis from acute pelvic inflammatory disease ${ }^{7}$ where patients tend to have raised white cells count and demonstrate signs of peritonism, which can make the differentiation between the two diagnoses on clinical grounds difficult. Non-specific idiopathic chronic abdominal pain syndromes are among the most challenging and demanding conditions to treat across the whole age spectrum. Potentially it can be unrewarding for both the patients and the surgical team ${ }^{11}$. Non-specific chronic abdominal pain is associated with poor quality of life ${ }^{16}$. Studies conducted with large community samples or hospital populations imply abdominal pain is a pervasive problem.

Many diagnostic and therapeutic procedures have been described in literature, but with little proof or evidence of success. Laparoscopy is one of the modalities that could be of benefit in such cases. Currently, diagnostic laparoscopy is getting wide acceptance as an alternative to laparotomy. This is primarily due to the growing experience and familiarity with laparoscopic surgeries, improvement in instrumentation as well as a high percentage of negative laparotomies ${ }^{18}$. Nonspecific abdominal pain (NSAP), generally defined as acute abdominal pain of less than 7 days duration and chronic more than 3 months and for which there is no diagnosis after examination and baseline investigations, is a common cause of emergency surgical hospitalization ${ }^{19}$. Diagnostic Laparoscopy may help in avoiding unnecessary laparotomy provide accurate diagnosis and help in planning the optimal therapy in these selected patients. Laparoscopy can identify abnormal findings and improve the outcome in a majority of patients with non-specific abdominal pain, as it allows surgeons to see and treat many abdominal conditions that cannot be diagnosed otherwise. In the present study we aim to evaluate the use of the laparoscopy in the diagnosis and management of patients with non-specific chronic and acute abdominal pain.

\section{MATERIAL AND METHODS}

The material consists of patient in all surgical units of P.B.M. and Associated Group of Hospital attached to S.P. Medical College, Bikaner. Inclusion Criteria: 1. All cases of undiagnosed (by conventional methods and investigations such as detailed history, clinical examination, blood counts, urine examination, USG abdomen, Plain $\mathrm{x}$ ray abdomen) nonspecific abdominal pain acute less than 7 days and chronic more than 3 months duration of both sex. 2. All cases of undiagnosed non-specific abdominal pain in patients more than 14years of age. Exclusion Criteria: 1. All cases of undiagnosed non-specific abdominal pain in patients less than 14 years of age.

\section{RESULTS}

This study includes 50 patients. In acute NSAP group 21 patients were present and in Chronic NSAP group 29 patients were included. We found that the mean age was 29.38 and 26.17 years in acute and chronic group respectively. In acute group female were 4 cases (19\%) and male were $21(81 \%)$, while in chronic group female were $17(58.6 \%)$ and male cases were $12(41 \%)$.

Table 1:Distribution Of Cases AccordingTo Symptoms \& Sign

\begin{tabular}{|l|l|l|l|l|}
\hline Symptoms \& Sign & acute & $\%$ & Chronic & $\%$ \\
\hline Pain abdomen & 21 & 100 & 29 & 100 \\
\hline Vomiting & 4 & 19 & 3 & 10.3 \\
\hline Fever & 3 & 14.2 & 2 & 6.8 \\
\hline Vomiting + fever & 2 & 9.5 & 1 & 3.4 \\
\hline
\end{tabular}

This table shows that, all patient had pain abdomen. In acute group additional $4(19 \%)$ cases had vomiting, 3(14.2\%) had 
fever, and $2(9.5 \%)$ had both vomiting and fever. While in chronic group $3(10.3 \%)$ cases had vomiting, $2(6.8 \%)$ had fever and $1(3.4 \%)$ case had both vomiting and fever.

We found that in $86 \%$ cases USG was inconclusive. USG was normal in $96 \%$ cases of acute group and $80 \%$ of cases of chronic group. We observe that in acute group TLC was raised in $5(23 \%)$ patients, $\mathrm{X}$-ray FPA was inconclusive in all cases, CT SCAN, endoscopy and barium study not done in acute cases. In chronic group TLC, $\mathrm{X}$-ray FPA, was normal in all cases, while ct scan done in 12 cases, 6 cases had positive finding, barium study done in 16 cases, only in one case it supported diagnosis, while endoscopy done in 7 cases, with no positive finding.

In our study appendicitis was most common finding in both acute and chronic group in $61.9 \%$ and $58.6 \%$ cases respectively. While gynecological causes $(10 \%)$ were second most common etiology among all the study group. In chronic group second most common diagnosis was adhesion obstruction in $13.4 \%$ cases and $3(10.2 \%)$ cases had normal finding in chronic group.

\section{Table 2:Efficacy Of Laparoscopy In Diagnosis (acute Group)}

\begin{tabular}{|l|l|l|l|l|l|l|}
\hline Diagnosis & $\begin{array}{l}\text { Final } \\
\text { Diagnosis }\end{array}$ & $\begin{array}{l}\text { Biopsy } \\
\text { Diagnosis }\end{array}$ & $\begin{array}{l}\text { Diagnosis } \\
\text { by visual } \\
\text { inspection }\end{array}$ & $\begin{array}{l}\text { Laparosc } \\
\text { opic } \\
\text { Diagnosis }\end{array}$ & $\begin{array}{l}\text { Lap } \\
\text { error }\end{array}$ & $\begin{array}{l}\text { Effica } \\
\text { cy of } \\
\text { Lap }\end{array}$ \\
\hline $\begin{array}{l}\text { Appendicular } \\
\text { pathology }\end{array}$ & 13 & 13 & 0 & 13 & 0 & 13 \\
\hline $\begin{array}{l}\text { Mesentric } \\
\text { Adenitis }\end{array}$ & 2 & 2 & 0 & 2 & 0 & 2 \\
\hline $\begin{array}{l}\text { Gynaecologi } \\
\text { cal cause }\end{array}$ & 3 & 0 & 3 & 3 & 0 & 3 \\
\hline $\begin{array}{l}\text { Ruptured } \\
\text { Liver } \\
\text { Abscess }\end{array}$ & 1 & 0 & 1 & 1 & 0 & 1 \\
\hline $\begin{array}{l}\text { Mackel's } \\
\text { Diverticulum }\end{array}$ & 2 & 2 & 0 & 2 & 0 & 2 \\
\hline Total & 21 & 17 & 4 & 21 & 0 & 21 \\
\hline
\end{tabular}

In above table, 17 (80\%) cases was confirmed by biopsy, while in $4(20 \%)$ cases diagnosis was made by visual inspection on laparoscopy alone, with no need of biopsy for further diagnosis while accuracy was $100 \%$ in acute group.

Table 3: Efficacy Of Laparoscopy In Diagnosis (chronic Group)

\begin{tabular}{|l|l|l|l|l|l|l|}
\hline Diagnosis & $\begin{array}{l}\text { Final } \\
\text { Diagno } \\
\text { sis }\end{array}$ & $\begin{array}{l}\text { Biopsy } \\
\text { Diagno } \\
\text { sis }\end{array}$ & $\begin{array}{l}\text { Diagnosis } \\
\text { by visual } \\
\text { inspection }\end{array}$ & $\begin{array}{l}\text { Laparoscop } \\
\text { ic Diagnosis }\end{array}$ & $\begin{array}{l}\text { Lap } \\
\text { error }\end{array}$ & $\begin{array}{l}\text { Effica } \\
\text { cy of } \\
\text { Lap }\end{array}$ \\
\hline $\begin{array}{l}\text { Appendic } \\
\text { ular } \\
\text { pathology }\end{array}$ & 17 & 17 & 0 & 17 & 0 & 17 \\
\hline Adhesion & 4 & 0 & 4 & 4 & 0 & 4 \\
\hline $\begin{array}{l}\text { Gynecolo } \\
\text { gical } \\
\text { cause }\end{array}$ & 2 & 0 & 2 & 2 & 1 & 1 \\
\hline $\begin{array}{l}\text { Mesentric } \\
\text { Adenitis }\end{array}$ & 1 & 1 & 0 & 1 & 0 & 1 \\
\hline $\begin{array}{l}\text { Intussusc } \\
\text { eption }\end{array}$ & 1 & 0 & 1 & 1 & 0 & 1 \\
\hline $\begin{array}{l}\text { Tubercul } \\
\text { osis } \\
\text { Stricture }\end{array}$ & 1 & 1 & 1 & 1 & 0 & 1 \\
\hline Normal & 3 & 0 & 0 & 0 & 3 & 0 \\
\hline Total & 29 & 19 & 8 & 26 & 4 & 25 \\
\hline
\end{tabular}

Efficacy of laparoscopy in chronic group was $86.2 \%$. Laparoscopy made correct diagnosis in $25(86.2 \%)$ cases, $3(10.3 \%)$ cases had normal study and $1(3.4 \%)$ case diagnosed as PID pain was not relieved.

After laparoscopy diagnosis, cases were managed |www.worldwidejournals.com | accordingly 15(71.5\%) cases were treated by laparoscopic intervention in acute group, while in chronic group 20(68.9\%) cases treated laparoscopically. Conversion needed in $2(9.5 \%)$ cases in acute and $4(13.7 \%)$ cases in chronic group. So overall $35(70 \%)$ cases managed by laparoscopy and $6(12 \%)$ cases were converted to laparotomy. Conversion rate in our study in acute group was $11.7 \%$ while in Chronic group was $16.6 \%$.

We found that unnecessary laparotomy saved in $9(18 \%)$ cases out of 50 cases. In acute group laparotomy saved in $4(19.2 \%)$ cases, out of these 2 cases had mesenteric adenitis, 1 case had small subserosal fibroid and 1 case had salpingitis. In chronic group laparotomy saved in $5(17.2 \%)$ cases out of these 3 cases had normal study while 1 case had mesenteric adenitis and 1 case had PID. Complication noted in this study were extra peritoneal insufflation of gas in $1(2.8 \%)$ case, bleeding at trocar site in $1(2.8 \%)$ case in laparoscopic group, while in laparotomy group $1(20 \%)$ case had wound infection. So complication in lap group was $5.6 \%$.and in complete study complication were noted in $3(6 \%)$ cases. Infection was treated by daily dressing and antibiotic treatment. while bleeding was controlled by pressure alone.

Table 4: Comparison Of Laparoscopic Diagnosis With Biopsy In Chronic Group

\begin{tabular}{|l|l|l|l|l|l|}
\hline Diagnosis & \multicolumn{3}{|l|}{ Biopsy } & Confirmed & $\%$ \\
\hline & Total & Taken & Not Taken & & \\
\hline $\begin{array}{l}\text { Appendicular } \\
\text { pathology }\end{array}$ & 17 & 17 & 0 & 17 & 100 \\
\hline Mesentric Adenitis & 1 & 1 & 0 & 1 & 100 \\
\hline Gynecological cause & 2 & 0 & 2 & 0 & - \\
\hline Adhesion & 4 & 0 & 4 & 0 & - \\
\hline Intususception & 1 & 0 & 1 & 0 & - \\
\hline Tuberculosis Stricture & 1 & 1 & 0 & 1 & 100 \\
\hline Normal & 3 & 0 & 3 & 0 & - \\
\hline Total & 29 & 19 & 10 & 19 & 65.5 \\
\hline
\end{tabular}

\section{DISCUSSION}

Present study was conducted in the department of general surgery, SP Medical College and A.G. Hospitals, Bikaner. Subsequent descriptions compare the results of our study with work of other standard series to evaluate the status of our work.

In present study the mean age in acute group was 29.38 and in chronic group 26.17. Gamal et al ${ }^{84}$ in year 2004 and Bareeq and Dayna $^{85}$ in the year 2007 did similar studies and their mean age was ranged from 27.8 to 31.0 years. In our study, all patients had pain abdomen. In acute group additional $4(19 \%)$ cases had vomiting, $3(14.2 \%)$ had fever and $2(9.5 \%)$. In study by Alvarado ${ }^{87}$ (1986) positive predictive value of vomiting and fever was 0.84 and 0.87 respectively.

In our study USG has positive finding in $7(14 \%)$ cases. USG was normal in $20(96 \%)$ in acute NSAP group and $23(80 \%)$ cases in chronic NSAP group. So among all the patients in the study group $43(86 \%)$ cases had normal USG. A study by Raman et $\mathrm{al}^{88}$ in 2004 found only $1(6 \%)$ out of 16 positive finding.

In our study on laparoscopy examination most common cause for acute NSAP was appendicitis in 13 cases (61.7\%). Study by Salky et $\mathrm{al}^{35}$ in 1997 found gynaecological cause for acute abdomen in 16(13.22\%) cases. which is similar to our study. Gynaecological causes were found in $3(14.3 \%)$ cases in acute group. One patient had small cortical cyst, one case had small subserosal fibroid and one had salpingitis.

In our study, diagnosis was possible in all cases of acute abdomen group. All 21(100\%) cases had obvious pathology on diagnostic laparoscopy. Study by Agrusa et $\mathrm{al}^{60} 2012$ showed that a definitive diagnosis was possible in over $96 \%$ cases and definitive treatment via laparoscopy was possible 
in most of these. In another study by Agresta et $\mathrm{al}^{48}$ in 2008 showed that definitive diagnosis was possible in $98.3 \%$ cases and all such patients were treated successfully by laparoscopic.

In acute group 4(19\%) cases including 2 gynaecological, one case of small fibroid and one case of salpingitis referred to gynaecology dept for conservative management. Two cases of mesenteric adenitis were managed conservatively. These cases did not require laparoscopic or laparotomy to treat thus avoiding unnecessary laparotomy. In chronic group 5(17.2\%) cases were managed conservatively avoiding unnecessary laparotomy in which 3 had normal study, 1 had mesenteric adenitis and 1 had PID.

Reported incidence of vascular injury is 0.1-6.4/1000 laparoscopy ${ }^{93}$ which included vessels of abdominal wall, omentum vessels, mesenteric vessels, vena cava and aorta. Opitz et $\mathrm{al}^{94} 2005$ in their study found that about $1.7 \%$ cases intraoperative course was complicated by internal bleeding or haematoma of abdominal wall which is comparable to our study. However in our study the complication reported in $3(6 \%)$ cases. $2(4 \%)$ cases in laparoscopy group include bleeding at trocar site in $1(2 \%)$ case and extra peritoneal insufflations of gas in $1(2 \%)$ case. While $1(2 \%)$ case in laparotomy group had minor wound infection which was treated by daily dressing and antibiotic. In conclusion Our study establishes role of laparoscopy as a safe and accurate modality in diagnosis of both acute and chronic abdominal pain in cases where diagnosis can't be made with physical examination and non invasive methods. Therapeutic laparoscopic is applicable in treatment of majority of such cases with minimal complications. Not only this, laparoscopy reduces the rate of unnecessary laparotomy but also it is of special practical benefits in under privileged areas where high end investigations are not available.

\section{REFERENCES-}

1. Laurell H, Hansson LE, Gunnarsson U. Diagnostic pitfalls and accuracy of diagnosis in acute abdominal pain.ScandJ Gastroenterol 2006;41(10):1126-31.

2. Flasar MH, Goldberg E. Acute abdominal pain. Med Clin North Am 2006; 90 : 481-503.

3. Bjerkeset T, Havik S, Aune KE, Rosseland A. Acute abdominal pain as cause of hospitalisation.Tidsskr Nor Laegeforen 2006;8(126): 1602-1604.

4. Rennie AT, Tytherleigh MG, Theodoroupolou K, Farouk R. A prospective audit of 300 consecutive young women with an acute presentation of right iliac fossa pain. Ann R Coll Surg Engl 2006;88: 140-3.

5. Golash V, Willson PD. Early laparoscopy as a routine procedure in the management of acute abdominal pain: a review of 1,320 patients. Surg Endosc 2005; 19(7):882-5.

6. Morishita K, Gushimiyagi M,Hashiguchi M,Stein GH,TokudaY.Clinical prediction rule to distinguish pelvic inflammatory disease from acute appendicitis in women of childbearing age. AmJEmerg Med 2007;25(2):152-7.

7. Lee CC, Golub R, Singer AJ, Cantu R Jr, Levinson H. Routine versus selective abdominal computed tomography scan in the evaluation of right lower quadrant pain:arandomized controlled trial.Acad Emerg Med 2007;14(2):117-22.

8. Likitnukul S, Wongsawat J, Nunthapisud P. Appendicitis-like syndrome owing to mesenteric adenitis caused by Salmonella typhi. Ann Trop Paediatr 2002; 22(1):97-9.

9. Prince RL. Evidence for an aetiological role for adenovirus type 7 in the mesenteric adenitis syndrome. MedJ Aust 1979;2(2):56-7.

10. Hawthorn IE. Abdominal pain as a cause of acute admission to hospital. J R Coll Surg Edinb 1992;37(6) :389-93. 